\title{
Forecasting of Surface Currents via Correcting Wind Stress with Assimilation of High-Frequency Radar Data in a Three-Dimensional Model
}

\author{
Lei Ren, Stephen Nash, and Michael Hartnett \\ Department of Civil Engineering \& Ryan Institute, National University of Ireland, Galway, Ireland \\ Correspondence should be addressed to Lei Ren; leirencomeon@gmail.com
}

Received 2 October 2015; Accepted 1 December 2015

Academic Editor: Hossein Tabari

Copyright (C) 2016 Lei Ren et al. This is an open access article distributed under the Creative Commons Attribution License, which permits unrestricted use, distribution, and reproduction in any medium, provided the original work is properly cited.

\begin{abstract}
This paper details work in assessing the capability of a hydrodynamic model to forecast surface currents and in applying data assimilation techniques to improve model forecasts. A three-dimensional model Environment Fluid Dynamics Code (EFDC) was forced with tidal boundary data and onshore wind data, and so forth. Surface current data from a high-frequency (HF) radar system in Galway Bay were used for model intercomparisons and as a source for data assimilation. The impact of bottom roughness was also investigated. Having developed a "good" water circulation model the authors sought to improve its forecasting ability through correcting wind shear stress boundary conditions. The differences in surface velocity components between HF radar measurements and model output were calculated and used to correct surface shear stresses. Moreover, data assimilation cycle lengths were examined to extend the improvements of surface current's patterns during forecasting period, especially for northsouth velocity component. The influence of data assimilation in model forecasting was assessed using a Data Assimilation Skill Score (DASS). Positive magnitude of DASS indicated that both velocity components were considerably improved during forecasting period. Additionally, the improvements of RMSE for vector direction over domain were significant compared with the "free run."
\end{abstract}

\section{Introduction}

The interaction of air currents with the sea surface is of great importance for studying coastal surface currents. Energy transfer from wind to water contributes to generation of surface currents [1]. Wind exerts a stress on the ocean's surface by turbulent transfer of momentum across the atmospheric boundary layer to generate ocean currents. Accurate definition of wind forcing in numerical models is obviously of great importance for developing reliable hindcast and forecast, as many model errors are derived from poor specification of boundary conditions [2]. In order to improve model forecasting ability, measured data from a HF radar system were assimilated into the model by updating the wind shear stress boundary condition.

In order to improve the forecasting ability of hydrodynamic modelling by taking advantage of available measurements such as radar surface currents and ocean currents from satellites, some researchers tried to enhance modelling performance using data assimilation techniques. Lewis et al. [3] corrected the shearing stress in model via assimilating Doppler radar current data into numerical ocean model. Minimum additional shearing stress was used to achieve a significant nudging of the model surface currents toward the basic characteristics of the observed filed of Doppler radar currents. Marmain et al. [4] assimilated HF radar surface currents in a model of the northwestern Mediterranean Sea. The wind forcing and lateral boundary-forcing components of a regional primitive equation numerical model were optimized by minimizing the difference between modelpredicted and radar-derived surface currents. Barth et al. [5] assimilated HF radar surface currents in a nested model of the West Florida Shelf (WFS). They carried out ensemble simulation of the WFS model under different wind forcing in order to estimate the error covariance of the model state vector and the covariance between ocean currents and winds. Barth et al. [6] used an ensemble scheme to obtain improved surface winds by assimilating high-frequency radar surface 
currents in German Bight. In their research, the uncertainty of the driving wind field was represented by an ensemble of perturbed wind forcing.

Ren et al. [7] used pseudo measurements to update surface currents in a test domain with Direct Insertion data assimilation. The sensitivity tests show that the effects of Direct Insertion data assimilation strongly depend on the frequency of the data assimilation cycle. The higher the data assimilation cycle frequency, the stronger the influence of the Direct Insertion on model forecasting. In general, there are two types of data assimilation schemes in oceanography: sequential and variational data assimilation [8]. The difference between sequential and variational data assimilation schemes is as follows. The analysis equation of the former is obtained by a linear combination of measurement states and background states, such as Optimal Interpolation, nudging, and Ensemble Kalman Filter data assimilation algorithms [911]. The analysis equation of the latter is derived by minimizing a cost function, which is made up of two terms: one is the distance between the analysis states and the background states, and the other is the distance between the analysis states and the observation states [12-14], such as threedimensional and four-dimensional variational data assimilation algorithms. These data assimilation schemes focus on directly correcting the surface currents by combining the measurements with model background states. Difficulties with data assimilation in coastal models are that it is not easy to obtain continuous measurements of surface currents over short time periods for sequential data assimilation and whilst wind forcing is of great influence on the generation of surface currents, it is not easy to measure high quality wind data over coastal waters.

The research presented in this paper is primarily concerned with aspects of data and techniques to enhance the forecasting capabilities of coastal hydrodynamic models. The paper briefly describes a three-dimensional hydrodynamic model of Galway Bay. The approach adopted uses surface current flow field data collected from a HF radar system to correct surface wind shear stress. Initially the radar data were compared against current measurements collected using an Acoustic Doppler Current Profile (ADCP) to benchmark the radar data.

One of the main goals of this study is to apply a data assimilation process that would be continuous for the following measurement period; this was achieved by implementing a method for correcting the model's wind shear stress. This data assimilation method transfers the difference between model states and measurement states to correction of wind shearing stress by assimilating HF radar data. The DASS was calculated and time series of velocity components and vector maps during forecasting period are shown to assess the improvements of data assimilation in the model.

The structure of this paper is as follows: Section 2 introduces the measurements from the radar system and ADCP in Galway Bay. A three-dimensional hydrodynamic model is presented in Section 3. Assimilation of radar surface currents into model is given in Section 3, followed by results in Section 4. Conclusions of this work are listed in Section 5.

\section{Measurements}

2.1. HF Radar. A CODAR (Coastal Ocean Dynamics Application Radar) system is a type of portable, land-based HF radar system which can measure the near-surface ocean currents in a coastal area [15]. One such system has been deployed in Galway Bay on Ireland's west coast (see Figure 1). The measurements obtained from the CODAR system are nearly real time. The rough ocean surface information is gained by the radar signal which scatters in many directions. When the radar signal scatters off a wave whose wave length is exactly equal to half of the transmitted signal wavelength [16, 17], the radar signal can return measurement information. A single HF radar station, or mast, determines the radial component of the surface currents relative to that station. Total surface currents velocities can be computed and displayed as vector maps by combining the radial surface current velocity components from two or more different masts. CODAR systems can provide rich datasets (in time and space), which can be used to explore the dynamical process of surface currents [18]. Operating frequency of the radars deployed in Galway Bay is $25 \mathrm{MHz}$. The temporal and spatial resolution is sixty minutes and 300 metres, respectively. The system is able to generate surface currents maps for the inner Galway Bay area (see Figure 1). The radar bandwidth is $500 \mathrm{kHz}$ at both stations.

In order to examine the impacts of data assimilation cycle lengths on forecasts, the radar data were temporally interpolated for the tests in Section 3.3. Reasons can be listed as follows: (1) Since hourly output of surface current vectors was obtained by averaging/merging data over a specified time period from the radar monitoring system, temporally linear interpolation of the output data was like an inverse process, which conveyed the averaged information to successive time steps over the measurement period. The linearly interpolated surface velocity data over this relatively short period were assumed to describe the properties of surface currents. (2) The ultimate goal of data assimilation in oceanography is to obtain improved estimates in models through making the best use of measured data; the idea of using the linearly interpolated measurements in time to frequently update the model background states was an experiment to assess the appropriate cycle length that would result in better forecasting states.

2.2. ADCP. A bed-mounted ADCP was deployed in Galway Bay (see point $A$ in Figure 1) within the region of CODAR measurement. Operating frequency of RDI Teledyne Workhorse Sentinel ADCP deployed in Galway Bay is a $600 \mathrm{kHz}$. Current speeds and directions were recorded over depth. The water depth is $20 \mathrm{~m}$ at measurement site. The ADCP measured currents over $2 \mathrm{~m}$ depth increments. The last cell close to the surface cannot be measured due to the side lobes interference area with the $2 \mathrm{~m}$ depth cells. Data were recorded every sixty minutes and the measurement period was from Julian Days 231 to 337 in 2013. Comparison of speeds and directions measured by HF radar and ADCP at location $\mathrm{A}$ is shown in Figures 3 and 4 . Radial speed comparison between the rotated ADCP data and Mutton 


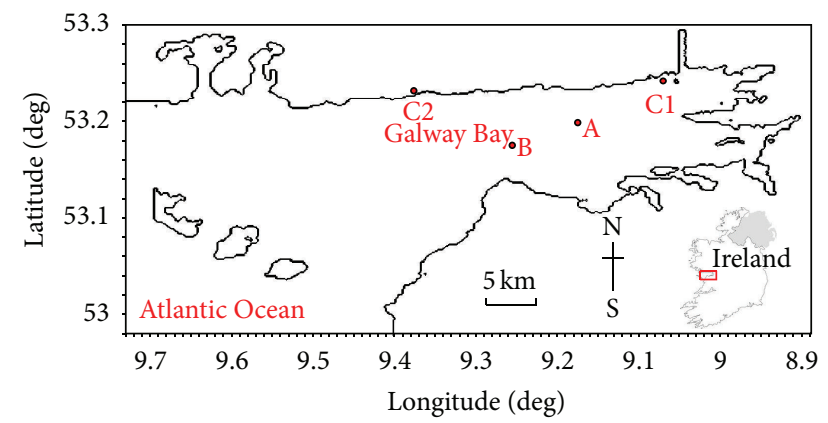

FIGURE 1: Deployment of HF radar system in Galway Bay. (C1 indicates the HF radar on Mutton Island station; $\mathrm{C} 2$ indicates the HF radar at Spiddle station; A indicates the location of ADCP.)

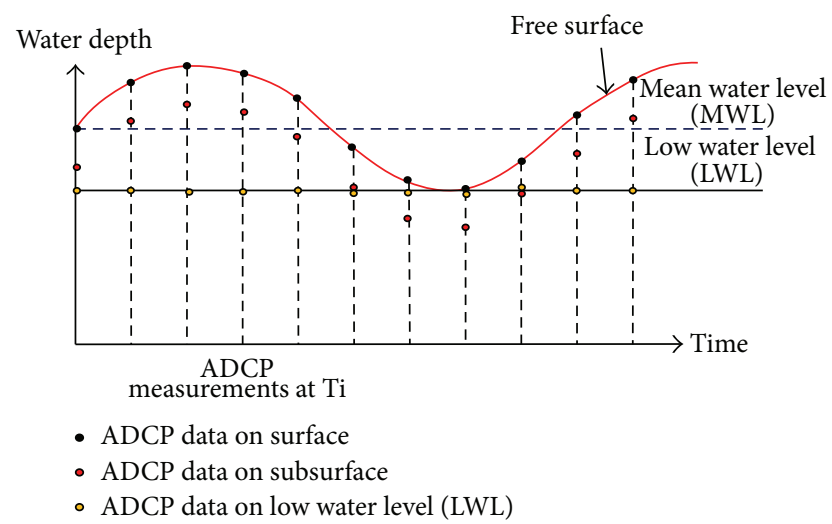

FIGURE 2: Water levels for ADCP data extraction.

Island station radial data is shown in Figure 5. Owing to the fact that ADCP surface currents were very noisy, speeds and directions of ADCP currents on low water level (LWL, see Figure 2) were used to intercompare with radar data as shown in Figures 3 and 4. Figure 2 shows the low water level of water column for intercomparisons.

Figure 3 shows that, in general, there is reasonably good agreement of speed trend between radar and ADCP data, but also differences exist. The magnitudes of radar data were bigger than ADCP data during some high speed timesteps such as near Julian Days 231.5, 233, and 235.7. This results because the last $3.2 \mathrm{~m}$ close to the surface can not be measured by ADCP due to the side lobes interference area with the $2 \mathrm{~m}$ depth cells and noisy surface conditions. Additionally, tough measurement conditions and observation accuracy can result in low quality of ADCP [19]. Thus, surface CODAR data were bigger than ADCP data on low water level at some timesteps having high speed. In order to quantify the correlation of surface velocity components between radar measurements and ADCP data, the method of complex correlation was used. Here, the authors took the components of the velocity vectors from both CODAR and ADCP as complex numbers in the following formula:

$$
\begin{aligned}
\widehat{U}_{\mathrm{CODAR}}(t) & =\widehat{u_{1}}(t)+\widehat{v_{1}}(t) i, \\
\widehat{U}_{\mathrm{ADCP}}(t) & =\widehat{u_{2}}(t)+\widehat{v_{2}}(t) i,
\end{aligned}
$$

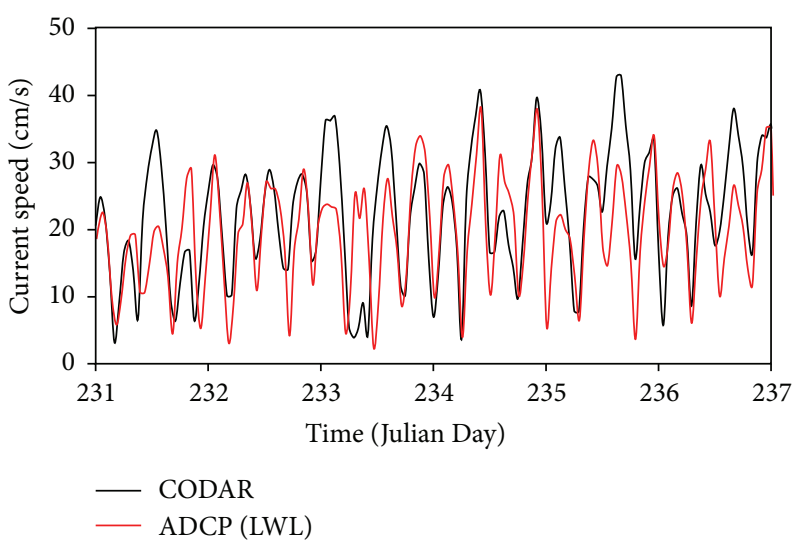

FIGURE 3: Speed of CODAR and ADCP current (low water level, 2013).

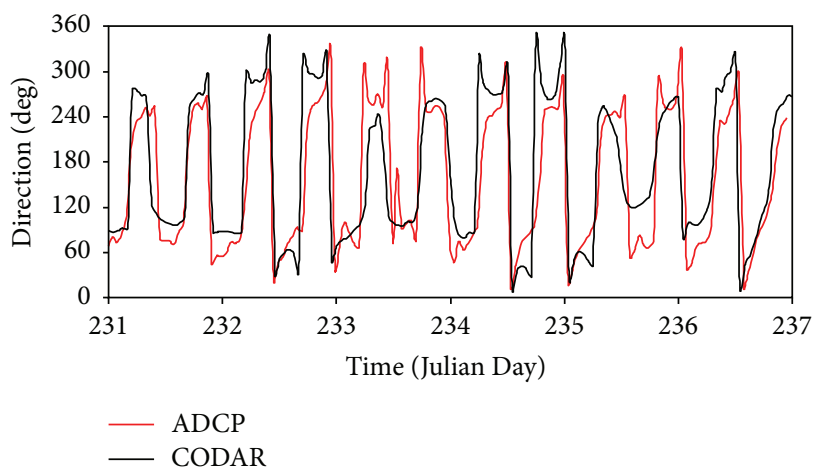

FIGURE 4: Direction of CODAR and ADCP current (low water level, 2013).

where $\widehat{U}_{\text {CODAR }}$ is CODAR measured velocity vector; $\widehat{U}_{\mathrm{ADCP}}$ is ADCP measured velocity vector; $\widehat{u_{1}}$ is the east-west velocity component vector of CODAR measurement; $\widehat{v_{1}}$ is the northsouth velocity component vector of CODAR measurement; $\widehat{u_{2}}$ is the east-west velocity component vector of ADCP measurement; $\widehat{v_{2}}$ is the north-south velocity component vector of ADCP measurement. The correlation amplitude $\rho_{c}$ and phase $\theta_{c}$ of the complex correlation are defined as $[10,20-$ 22]

$$
\begin{aligned}
& \rho_{c}=\sqrt{\operatorname{Re}^{2}+\operatorname{Im}^{2}}, \\
& \theta_{c}=\tan ^{-1} \frac{\left\langle\widehat{u_{1}} \widehat{v_{2}}-\widehat{u_{2} \widehat{v_{1}}}\right\rangle}{\left\langle\widehat{u_{1}} \widehat{u_{2}}+\widehat{v_{1}} \widehat{v_{2}}\right\rangle},
\end{aligned}
$$

where

$$
\begin{aligned}
& \operatorname{Re}=\frac{\left\langle\widehat{u_{1}} \widehat{u_{2}}+\widehat{v_{1}} \widehat{v_{2}}\right\rangle}{\left\langle\widehat{u_{1}^{2}}+\widehat{v_{1}^{2}}\right\rangle^{1 / 2}\left\langle\widehat{u_{2}^{2}}+\widehat{v_{2}^{2}}\right\rangle^{1 / 2}} \\
& \operatorname{Im}=\frac{\left\langle\widehat{u_{1}} \widehat{v_{2}}-\widehat{u_{2}} \widehat{v_{1}}\right\rangle}{\left\langle\widehat{u_{1}^{2}}+\widehat{v_{1}^{2}}\right\rangle^{1 / 2}\left\langle\widehat{u_{2}^{2}}+\widehat{v_{2}^{2}}\right\rangle^{1 / 2}} .
\end{aligned}
$$

The angle brackets stand for averaged value or mean. Dimensionless intermediate variables $\mathrm{Re}$ and $\mathrm{Im}$ are used 


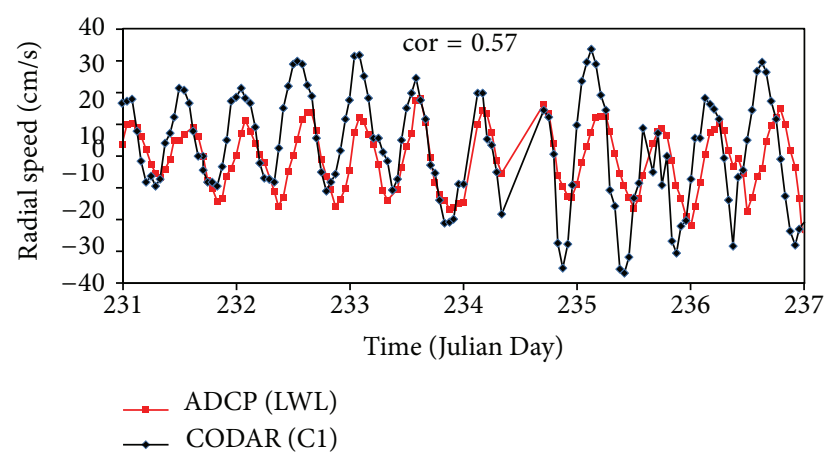

FIgURE 5: Radial currents time series. (Positive values indicate the current direction towards the Mutton Island (C1) station; negative values indicate the current direction away from the Mutton Island station.)

to simplify the expression of correlation $\rho_{c}$. The correlation $\rho_{c}$ is independent of any coordinate system and reflects the correlation relationship of the two vectors. The magnitude of $\rho_{c}$ represents an overall measure of correlation. Phase $\theta_{c}$ in degrees stands for the average veering of two vectors, while the average veering is meaningful only if the value of correlation $\rho_{c}$ is high [10]. The bigger the value of the amplitude, the stronger the correlation between two vectors. The value of correlation amplitude close to 1 and phase close to zero implies an excellent comparison between the two vector time series. In this research, the two time series of vectors are the radar and ADCP measurements at point A in Figure 1; the computation time period is from Julian Day 220 to Julian Day 243 in 2013. The data from ADCP used here are the low water level data. The correlation and phase between time series data of CODAR and ADCP are 0.57 and $-17.26^{\circ}$, respectively. Based on Taylor's labeling system about correlation [23], modest correlation (from 0.36 to 0.67 ) exists between the CODAR and ADCP data, which provided confidence in using the radar data in the following application. Additionally, the value of the correlation coefficient (0.57) using ADCP data at low water level in this study was comparable to the value 0.62 in Kelly et al.s study [19]. They compared $0.5 \mathrm{~m}$ radar data with ADCP currents at $2.5 \mathrm{~m}$.

Barth et al. [5] compared radial currents by averaging two days' data between the CODAR and ADCP measurements; the ADCP data were rotated to the HF radar antenna in their research. Correlation coefficient between the two datasets was 0.75 . The same method was used in this work to further investigate two available datasets from the CODAR and ADCP. The rotated ADCP data were compared with the radial currents from C1 station (see Figure 1) as shown in Figure 5, positive values indicate direction is towards the CODAR station $\mathrm{Cl}$, and negative values indicate the direction is away from the CODAR station $\mathrm{Cl}$. The correlation coefficient over the comparison period between the two datasets is 0.57 , which has the same magnitude as the calculated complex correlation using (2)-(4). Based on Taylor's labeling system of correlation coefficient [23], modest correlation also existed in the radial currents between the CODAR data and ADCP data.
2.3. Hydrodynamic Model. The three-dimensional numerical model EFDC was used to simulate the hydrodynamic circulation of Galway Bay. EFDC was developed at the Virginia Institute of Marine Science and is currently supported by the U.S. Environmental Protection Agency (EPA) [24]. It comprises four linked modules: hydrodynamic, water quality and eutrophication, sediment transport, and toxic chemical transport and fate; only the hydrodynamic module was used for this research. This module solves the three-dimensional, vertically hydrostatic, free surface, turbulent averaged equations of motions for a variable density fluid. The model uses a sigma vertical coordinate system and either regular or curvilinear, orthogonal, horizontal coordinates. The model has been applied to a variety of modelling studies [25-27].

In the present research, a model of Galway Bay (see Figure 1) was developed using a regular grid coordinate system. The horizontal plane dimension of the simulation domain is approximately $55 \mathrm{~km}$ in length and $35 \mathrm{~km}$ in width. The water depth of the area covered by the radar system is in the range of $10-40 \mathrm{~m}$. Galway Bay, which is different from other open coastal domains covered by CODAR observation system such as German Bight [6] and Monterey Bay [21], is a semienclosed area. The dynamics within Galway Bay are mainly influenced by oceanic flows to the bay from the adjacent shelf and wind driven currents. Oceanic flows enter the bay mainly through the southern sounds and circulate with the bay before exiting through the North Sound [28]. Meteorological conditions in Galway Bay were mainly influenced by the Atlantic weather system [29]. The main wind direction in Galway Bay area is southwest [30].

A $150 \mathrm{~m}$ horizontal spatial resolution was employed yielding $380 \times 241$ grid cells. Variable vertical layer thicknesses were used in the model with a thinner layer at the top and bottom of the water column and thicker layers in the middle. This structure ensured that wind shear can properly propagate from the surface layer to the subsurface layers, thereby ensuring that wind forcing was not overly damped by tidal forcing. The simulation period was categorized as three types: (a) spin-up period, Julian Days 211-220 in 2013; (b) assimilation period, Julian Days 220-228.04; (c) forecasting period: after Julian Day 228.04. The wind data, from Informatics Research Unit for Sustainable Engineering (IRUSE), which is located in the campus of National University of Ireland, Galway (NUIG), and tidal water elevation time series from Oregon State University Tidal Prediction Software (OTPS) are used to drive the model. The time interval of NUIG measurements is one minute. The averaged NUIG wind speed from Julian Days 220 to 230 is $2.75 \mathrm{~m} / \mathrm{s}$. Surface wind shear stress in EFDC model is typically calculated as $[31,32]$

$$
\frac{A_{v}}{H} \frac{\partial}{\partial z}(u, v)=\left(\tau_{x z}, \tau_{y z}\right)=C_{D} \sqrt{U_{w}^{2}+V_{w}^{2}}\left(U_{w}, V_{w}\right),
$$

where $A_{v}$ is the vertical viscosity; $\tau_{x z}$ and $\tau_{y z}$ are shear stresses at the surface $(z=1) ; U_{w}$ and $V_{w}$ are wind speed components at $10 \mathrm{~m}$ above the water surface; $C_{D}$ is wind-stress coefficient; $H$ is water depth. 
$\mathrm{Wu}$ [33] used the following format to define the windstress coefficient:

$$
C_{D}=\left(0.8+0.065 U_{10}\right) \times 10^{-3},
$$

where

$$
U_{10}=\sqrt{U_{w}^{2}+V_{w}^{2}} \text {. }
$$

Equations (16) and (17) are default format of wind-stress coefficient in EFDC. Another important parameter in coastal models is the bottom roughness height as it influences the current distribution over depth and the energy balance of the water column. The bottom drag coefficient $C_{b}$ in EFDC model is given as $[24,31]$

$$
\begin{aligned}
C_{b} & =\left[\frac{k}{\ln \left(\Delta_{\mathrm{bl}} / 2 \sigma_{0}\right)}\right]^{2}, \\
\sigma_{0} & =\frac{Z_{0}}{H},
\end{aligned}
$$

where $k$ is the von Karman constant; $\Delta_{\mathrm{bl}}$ is the dimensionless bottom layer thickness; $\sigma_{0}$ is the dimensionless roughness height; $Z_{0}$ is the dimensional roughness height in metre; $H$ is the water depth.

Wang et al. [32] set the bottom roughness to be $0.003 \mathrm{~m}$ to simulate the tidal currents in Jiaozhou Bay [32]. They found the relative error was around $5.9 \%$ of modelling results when bottom roughness was $0.003 \sim 0.01 \mathrm{~m} ; 15 \%$ with $0.01 \sim 0.02 \mathrm{~m}$ bottom roughness height. The range of bottom roughness height for their models is less than $0.02 \mathrm{~m}$. Sensitivity experiments of bottom roughness in Galway Bay are undertaken when forcing the model with NUIG winds. The range of bottom roughness height for our models is less than $0.005 \mathrm{~m}$. The RMSE between model results and HF radar measurements is calculated with (10)-(12). RMSE of individual surface velocity components was firstly calculated with (10) and (11); then total $\operatorname{RMSE}(u, v)$ was computed with (12):

$$
\begin{aligned}
\operatorname{RMSE}^{j}(u) & =\sqrt{\frac{\sum_{i=1}^{N_{j}}\left(u_{\text {CODAR }}-u_{\text {model }}\right)^{2}}{N_{j}}}, \\
\operatorname{RMSE}(u) & =\frac{\sum_{j=1}^{n} \operatorname{RMSE}^{j}(u)}{n}, \\
\operatorname{RMSE}(u, v) & =\sqrt{\operatorname{RMSE}(u)^{2}+\operatorname{RMSE}(v)^{2}},
\end{aligned}
$$

where $u_{\text {CODAR }}$ is the HF radar measured surface velocity east-west component; $u_{\text {model }}$ is the modelled component; $\operatorname{RMSE}^{j}(u)$ is the Root-Mean-Squared-Error of east-west velocity component at time step $j ; n$ is the number of time steps; $N_{j}$ is the number of calculation points at time step $j$.

The authors focused on obtaining good simulation of surface current patterns. Influences of bottom roughness on simulating surface currents in Galway Bay were not significant according to the RMSE values among bottom roughness height test models. The best bottom roughness height $0.001 \mathrm{~m}$ was used for assimilation models based on obtaining minimum RMSE values. This best model as shown in Figure 6 is marked as model BG with NUIG wind and $0.001 \mathrm{~m}$ bottom roughness height for the following studies.

\section{Data Assimilation via Correcting Wind Stress}

3.1. Data Assimilation Algorithm. The NUIG wind data enable the model to achieve reasonably good agreement with $\mathrm{HF}$ radar measurements. In order to improve the forecasting ability of the numerical model, wind shearing stress over the model domain is updated by assimilating HF radar measurements into the model. This data assimilation method as used by Lewis et al. [3] does not work by directly combining the HF radar measurements with modelled currents, but instead by correcting the wind shearing stress by calculating the difference between modelled and measured surface currents [34-36]. One advantage of this data assimilation scheme is that the correction of the wind shearing stress prolongs the influence of the updating through the following data assimilation cycle. In reality, we are more interested in the model's forecasting ability. Forecasting models via assimilating radar data based on model BG were run. All of the conditions are the same as model BG except for the fact that the data assimilation period is Julian Days 220-228.04. Here, correction of wind shearing stress by assimilating $\mathrm{HF}$ radar measurements focuses on improving patterns of surface currents. A complete data assimilation system is comprised of three parts: (i) a numerical model, which describes the dynamic process in a mathematic way; (ii) a batch of observations of variables of interest; (iii) a data assimilation algorithm to combine the measurements states with model background states. The flowchart of indirection data assimilation algorithm in Lewis et al.s study [3] is shown in Figure 7.

Lewis et al. [3] expressed the additional shearing stress $\tau_{s}$ as

$$
\tau_{s}=\rho C\left(u^{\mathrm{CODAR}}-u^{\text {model }}\right)\left|u^{\mathrm{CODAR}}-u^{\text {model }}\right|
$$

where $u^{\text {CODAR }}$ is the HF radar measured east-west surface velocity component, $u^{\text {model }}$ is the model-predicted east-west surface velocity component, $\rho$ is the water density, and $C$ is the tuning coefficient. In order to produce gentle nudging of the model background states to the observed data, the minimal east-west shearing stress from their derivation is given as [3]

$$
\begin{aligned}
\tau_{i, j} & =\rho C\left(u_{i, j}^{\mathrm{CODAR}}-u_{i, j}^{\text {model }}\right) \\
& \frac{\int\left(u_{i, j}^{\mathrm{CODAR}}-u_{i, j}^{\text {model }}\right)^{2}\left|u^{\mathrm{CODAR}}-u^{\text {model }}\right| d A}{\int\left|u^{\mathrm{CODAR}}-u^{\text {model }}\right|^{2} d A}
\end{aligned}
$$

where $A$ is the assimilation domain and $i, j$ are the model grid coordinates. Since a single wind forcing time series was used in our model, the mean east-west shearing stress $\overline{\tau_{t}}$ over the 


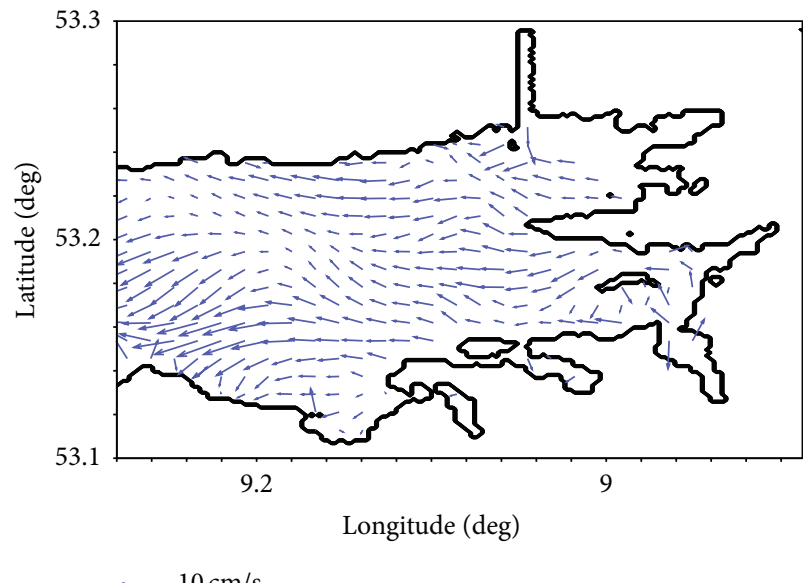

(a)

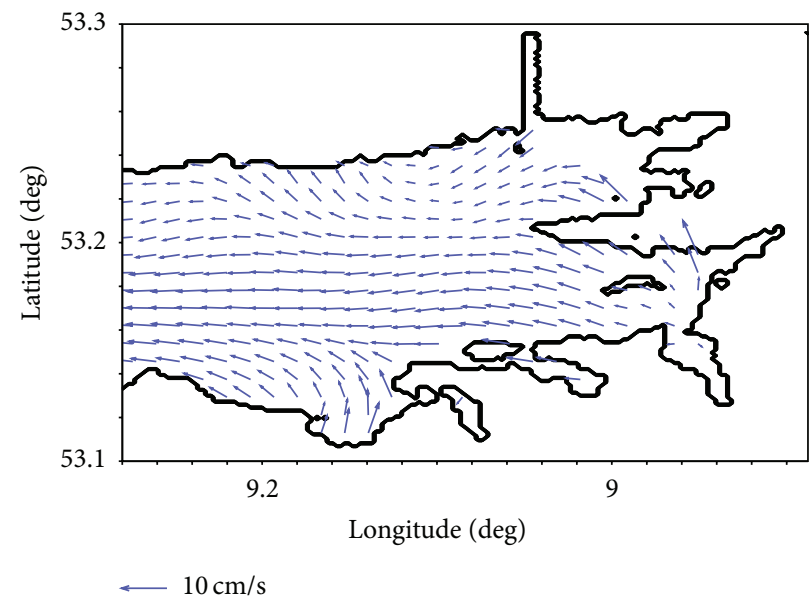

(b)

Figure 6: Mean vector maps during Julian Days 220-230, 2013. (a) is results from model BG; (b) is the radar data.

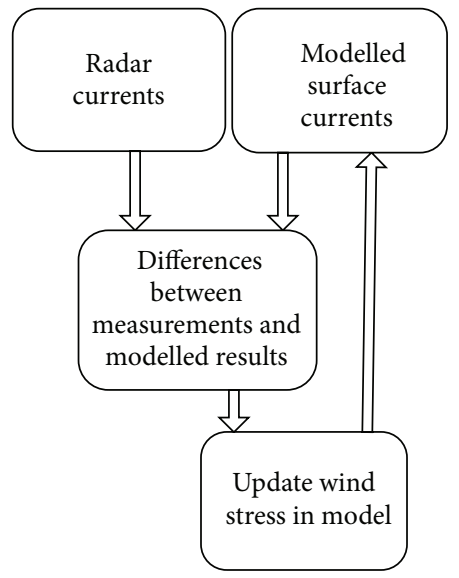

FIGURE 7: Flowchart of indirect data assimilation algorithm via correcting wind forcing.

assimilation domain is added to original wind shearing stress. The mean shearing stress over domain is calculated as

$$
\overline{\tau_{t}}=\frac{\sum \tau_{i, j}}{N_{t}}
$$

and the total east-west surface shearing stress $\tau$ is given as

$$
\tau=\tau_{w}+\overline{\tau_{t}}
$$

where $N_{t}$ is the number of assimilation grid points at step $t$ and $\tau_{w}$ is the original east-west wind shearing stress. Northsouth wind shearing stress was updated using the same equations (13)-(16).

3.2. Assimilation Parameter. In the data assimilation scheme undertaken by Lewis et al. [3], the coefficient $C=(0.8+$ $\left.0.065 U_{10}\right) \times 10^{a}$ was used as a tuning parameter, which was determined by the RMSE between modelling results and HF radar measurements in this research. A bigger value of coefficient $C$ provides a stronger emphasis on rendering the model to follow HF radar measurements. Lewis et al. tested the coefficient with orders of $a=-3$ and $a=-2$. The data assimilation model with $a=-2$ can generate better results when comparing with the measurements. Three different tuning coefficient values were investigated in this research. Four models were therefore considered as follows: model BG (without data assimilation), and three data assimilation (DA) models: DA1 with $a=-3$, DA2 with $a=-2$, and DA3 with $a=-1$. The averaged RMSE values were calculated using (10)-(12) which are presented in Table 1.

RMSE values shown in Table 1 were calculated during an eight-day hindcasting period (Julian Days 220-228.04) to select the best value of tuning coefficient $a$. Appropriate tuning coefficient $a$ was selected by producing the minimum RMSE. The reason for using this method lies in the implicit hypothesis: good performance during hindcasting period via assimilating radar data can have positive effects on forecasting. Values of total $\operatorname{RMSE}(u, v)$ showed that all indirect data assimilation models via correcting wind force improved the results during hindcasting period compared with the "free run" BG. The values of RMSE among indirect data assimilation models were very close. The improvement of model DA3 $(a=-1)$ was biggest $4.6 \%$ compared with the "free run." The bigger value of parameter $C_{\mathrm{DA}}$ resulted in smaller RMSE values for both velocity components. This trend was similar to the study of Lewis et al. [3]. This meant that the intensity of added wind stress via assimilating radar data affected the simulation of surface currents during hindcasting period. In order to obtain good forecasting, $C=10^{-1}$ was viewed as the best one which would improve model performance and was used in the subsequent data assimilation models.

In order to explore the forecasting improvements after hourly assimilating the surface currents in model to correct wind shearing stress, time series comparisons of DA3 modelled surface velocity components and HF radar measurements at point B (see Figure 1) are shown in Figures 8 and 9. 
TABLE 1: RMSE of data assimilation models.

\begin{tabular}{lcccc}
\hline Model & BG & DA1 & DA2 & DA3 \\
\hline$a$ & NDA & -3 & -2 & -1 \\
$\operatorname{RMSE}(u, \mathrm{~cm} / \mathrm{s})$ & 8.7093 & 8.7017 & 8.6426 & $\mathbf{8 . 3 2 7 4}$ \\
$\operatorname{RMSE}(v, \mathrm{~cm} / \mathrm{s})$ & 7.6972 & 7.6933 & 7.6195 & $\mathbf{7 . 3 1 3 2}$ \\
$\operatorname{RMSE}(u, v, \mathrm{~cm} / \mathrm{s})$ & 11.6232 & 11.6083 & 11.5218 & $\mathbf{1 1 . 0 8 2 8}$ \\
\hline
\end{tabular}

Note: NDA indicates the model without data assimilation.

East-west velocity component in model BG is shown to compare well with the radar data; the influence of hourly update of wind shearing stress did not obviously affect it. However, the model BG had a tendency not to accurately generate northsouth velocity component prior to the implementation of data assimilation as shown in Figure 9. Effects of hourly updates of wind shearing stress using the radar data were also very weak for north-south velocity component.

In order to further enhance the model forecasting capability via assimilating the radar data based on findings in Ren et al. [7], tests of data assimilation cycle lengths were performed in the following section. In this research, we focused on improving the forecasting performance of northsouth velocity component.

3.3. Data Assimilation Cycle Length Tests. In order to further improve model forecasts, the radar data, which were temporally linearly interpolated, were assimilated into the threedimensional model to correct the wind stress. Five different data assimilation cycle lengths, (1) each model timestep (MS), (2) one minute, (3) five minutes, (4) fifteen minutes, and (5) sixty minutes, were applied in the data assimilation models to study the influence of data assimilation cycle lengths on forecasts. Test models and RMSE values during the $+12 \mathrm{~h}$ forecasting period are given in Table 2. RMSE values were calculated using (10)-(12).

Table 2 shows that indirect data assimilation via correcting wind force with one-minute data assimilation cycle length had the minimum total RMSE $9.9446 \mathrm{~cm} / \mathrm{s}$ over $+12 \mathrm{~h}$ forecast compared with radar data. The improvement of north-south velocity component was $9.4 \%$ compared with the "free run" (model BG). Indirect data assimilation models with different data assimilation cycle lengths outperformed the "free run" during the forecasting period, except for the indirect data assimilation model DA4, which updated the model background states at each timestep. Since the added wind stress was obtained from the differences between radar data and model background states, frequent transfer of the velocity difference to wind stress such as at each timestep may have resulted in significant disturbance to the model background states. Model DA5 was viewed as the best data assimilation via correcting wind shearing stress using radar data for Galway Bay.

3.4. Assessment Method. Besides comparison of vector fields and time series, in order to further quantify and assess the improvement in accuracy of modelled surface currents achieved by assimilating radar currents to correct the wind

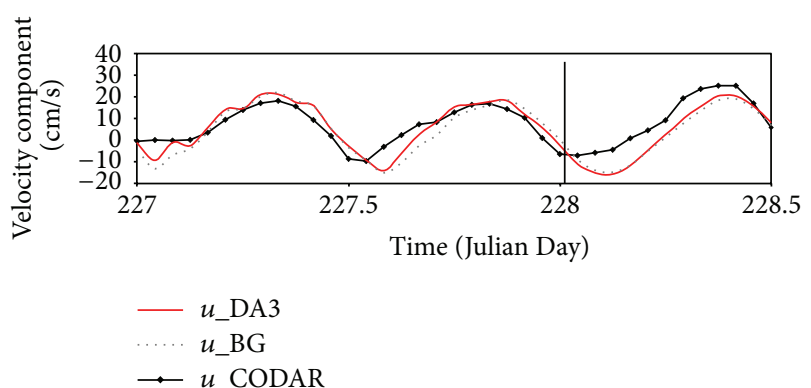

FIGURE 8: East-west surface velocity component (point B in Figure 1).

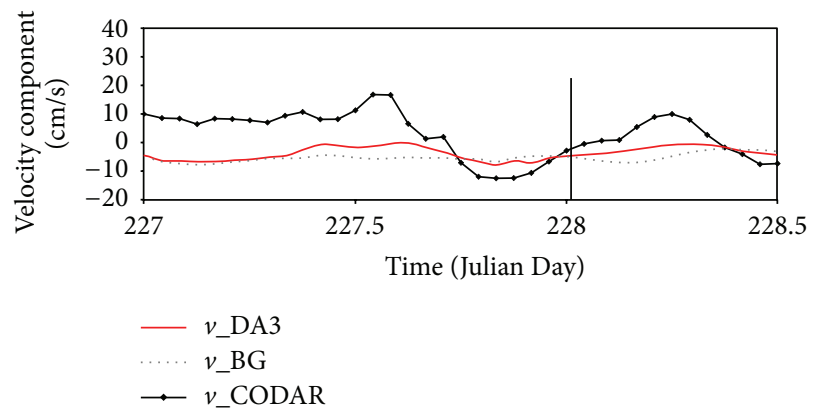

FIGURE 9: North-south surface velocity component (point B in Figure 1).

shear stress in model, the DASS is calculated in the domain covered by the radar system over time as [37]

$$
\begin{array}{r}
\text { DASS }=1-\frac{\operatorname{MSE}\left(v^{\mathrm{CODAR}}, v^{\mathrm{DA}}\right)}{\operatorname{MSE}\left(v^{\mathrm{CODAR}}, v^{0}\right)}, \\
\operatorname{MSE}\left(v^{\mathrm{CODAR}}, v^{\mathrm{DA}}\right)=\frac{\sum_{i=1}^{n}\left(v_{i}^{\mathrm{CODAR}}-v_{i}^{\mathrm{DA}}\right)^{2}}{n},
\end{array}
$$

where $v^{\mathrm{DA}}, v^{0}$ are the outputs from the model with (model DA5) and without (model BG) data assimilation, respectively; $v^{\mathrm{CODAR}}$ is the data from HF radar system; $n$ is the number of comparison points in data assimilation domain. The same formula as shown in (18) is also used to compute $\operatorname{MSE}\left(v^{\mathrm{CODAR}}, v^{0}\right)$.

If DASS is greater than zero, it means that the data assimilation model improves the forecasting compared with no data assimilation. If DASS is less than zero, it means the data assimilation contaminates the basic dynamic processes in the model resulting in deterioration in model accuracy. The model BG without data assimilation was taken as the reference model during the whole simulation period.

\section{Results}

4.1. Patterns of Surface Currents. In order to study the patterns of surface currents after assimilating radar data into models, vector maps at two typical forecasting timesteps (03:00 and 06:00 Julian Day 228) are shown in Figure 10. 


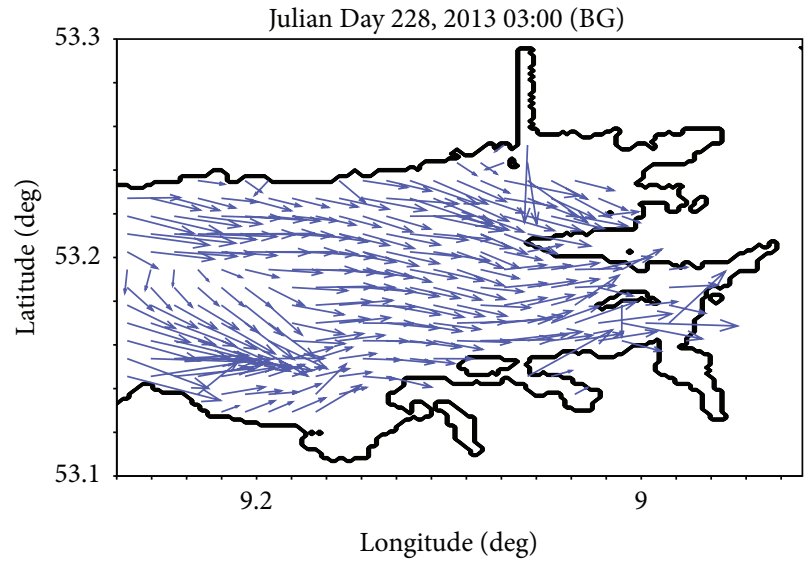

$\longleftarrow 10 \mathrm{~cm} / \mathrm{s}$

(a1)

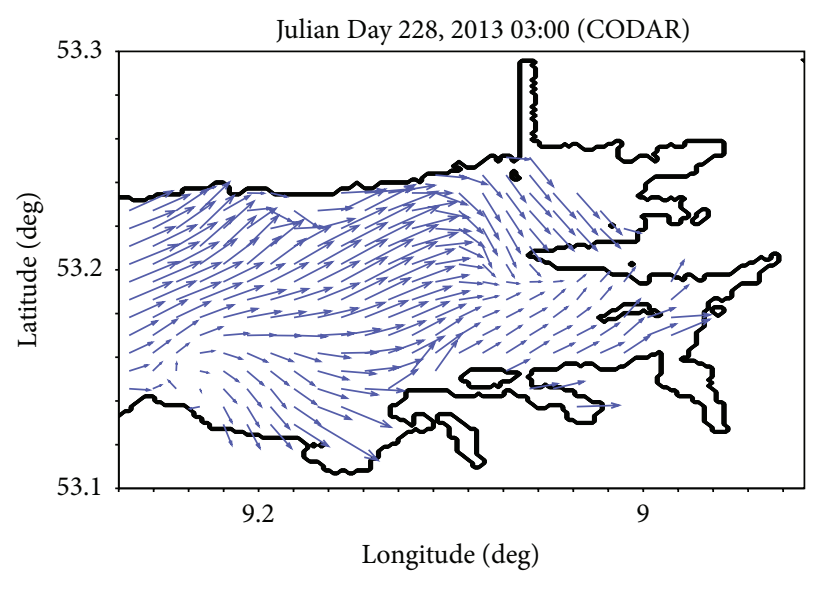

$\longleftarrow 10 \mathrm{~cm} / \mathrm{s}$

(b1)

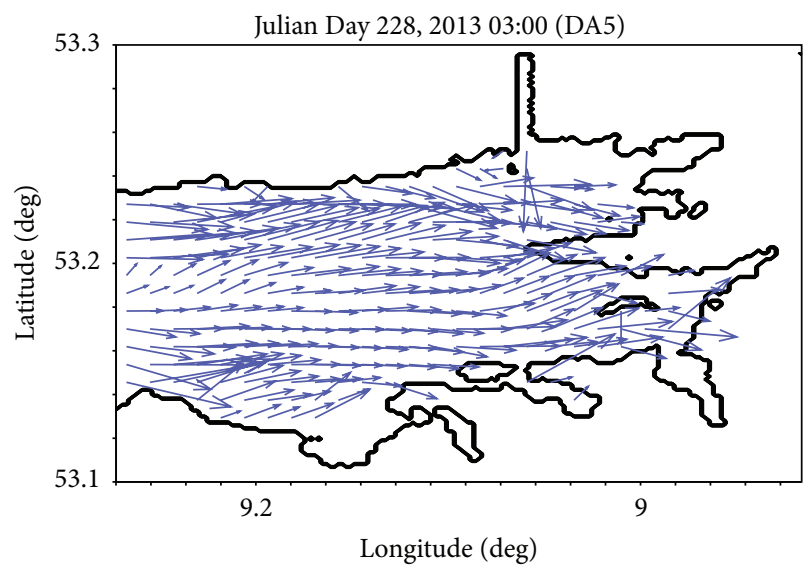

$\longleftarrow 10 \mathrm{~cm} / \mathrm{s}$

(c1)

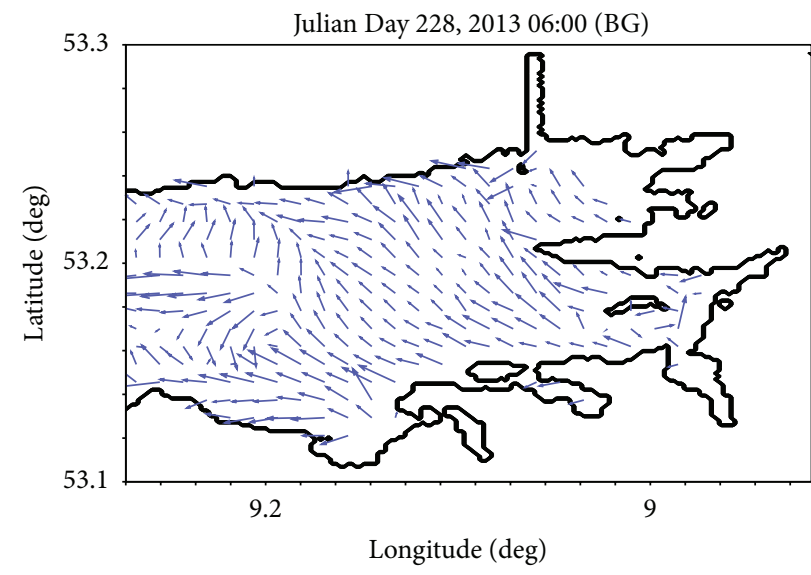

$\longleftarrow 10 \mathrm{~cm} / \mathrm{s}$

(a2)

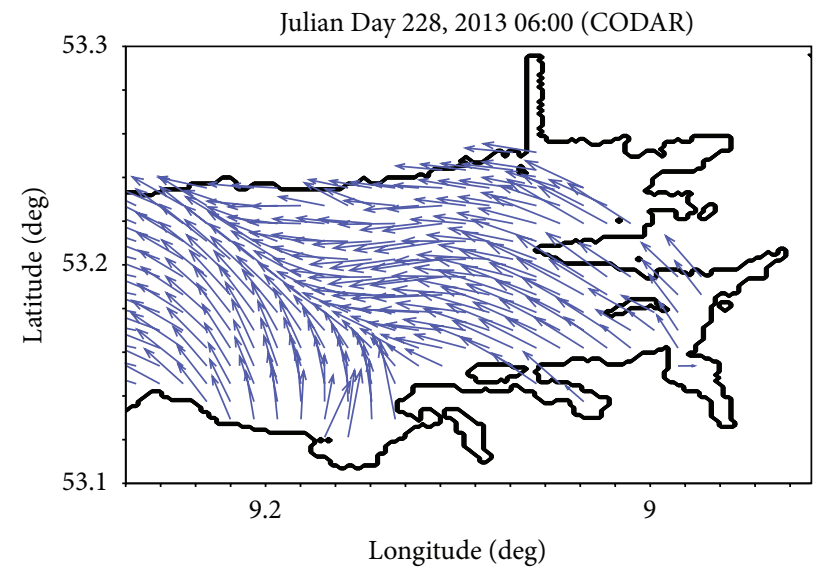

$\longleftarrow 10 \mathrm{~cm} / \mathrm{s}$

(b2)

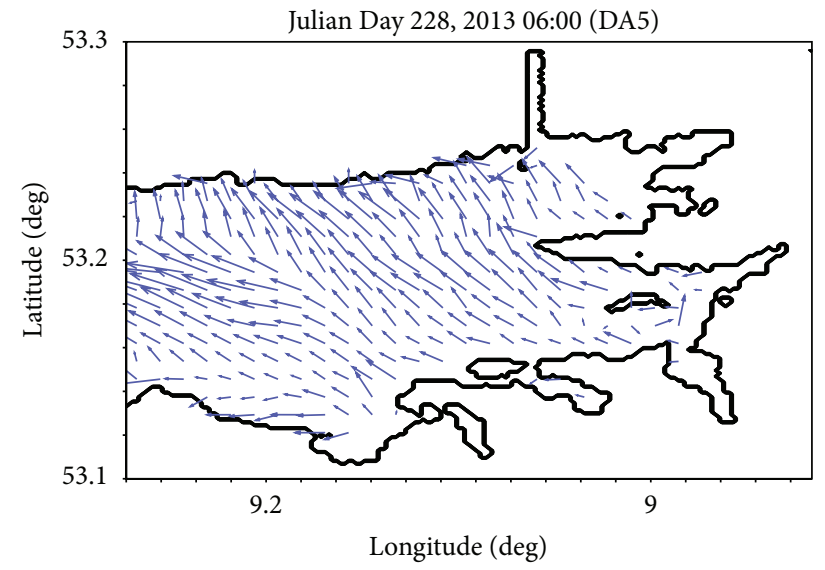

(c2)

FIgURE 10: Vector maps at 03:00 and 06:00 Julian Day 228. 
TABLE 2: Indirect data assimilation cycle length test models.

\begin{tabular}{lcccccc}
\hline Model & BG & DA4 & DA5 & DA6 & DA7 & DA3 \\
\hline Cycle length (mins) & NDA & MS & 1 & 5 & 60 \\
RMSE $(u, \mathrm{~cm} / \mathrm{s})$ & 8.2131 & 10.0689 & 8.2748 & 8.2713 & 8.2654 & 8.2809 \\
$\operatorname{RMSE}(v, \mathrm{~cm} / \mathrm{s})$ & 6.0902 & 6.7671 & 5.5157 & 5.5544 & 5.5632 \\
$\operatorname{RMSE}(u, v, \mathrm{~cm} / \mathrm{s})$ & 10.2247 & 12.1316 & $\mathbf{9 . 9 4 4 6}$ & 9.9633 & 9.9632 & 15.6889 \\
\hline
\end{tabular}

TABLE 3: RMSE of vector direction (degrees).

\begin{tabular}{lcc}
\hline Time/model & BG & DA5 \\
\hline $03: 00$ & 39.4507 & 33.5558 \\
$06: 00$ & 49.4637 & 42.9707 \\
$09: 00$ & 23.9298 & 23.1958 \\
$12: 00$ & 52.729 & 51.7525 \\
\hline
\end{tabular}

Figure 10 shows that, in general, model DA5 can produce closer patterns of surface currents to radar data than model BG without data assimilation. In order to quantitatively assess the improvements of surface current circulation during forecasting period, the averaged RMSE of vector directions of surface currents over simulation domain were computed between modelled results and the radar data at four timesteps on Julian Day 228 and shown in Table 3. Firstly, the RMSE values were calculated at each model grid; then a single RMSE value at each analysis timestep was obtained by averaging the RMSE values over domain.

Table 3 shows the best data assimilation model DA5 improved the pattern of surface currents at these forecasting timesteps. The improvements of vector direction over domain decreased in time; the improvements were $14.9 \%$ and $13.1 \%$ at 03:00 and 06:00 compared with the "free run" BG, respectively.

4.2. Time Series of Surface Velocity Components. In order to efficiently and fairly assess the forecasting performance, time series of surface velocity component at point B (see Figure 1) over $+6 \mathrm{~h}$ forecasting period are shown in Figures 11 and 12 .

The best data assimilation model DA5 improves performance for both surface velocity components over $+6 \mathrm{~h}$ forecasting compared with "free run" BG.

4.3. Data Assimilation Skill Score. Here, since good match of east-west velocity component between modelled results and the radar data was obtained as shown in Figure 8, we were interested in improving the north-south surface velocity component. The DASS using (17) and (18) is $15.2 \%$ and $7.6 \%$ for the north-south surface velocity component and total surface velocity during our hindcasting period, respectively. It confirms that the correction of wind shearing stress by assimilating HF radar measurements into the model enhances the modelling performance, especially for the strongly windinfluenced north-south velocity component.

In order to assess the forecasting improvements in model, the DASS of both surface velocity components was calculated during $+6 \mathrm{~h}$ forecasting period using (17). The averaged DASS

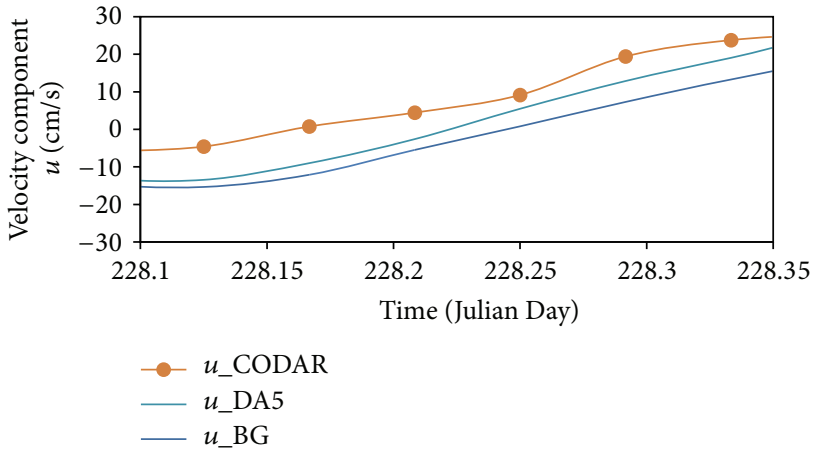

FIGURE 11: East-west velocity component time series during forecasting period at point $B$.

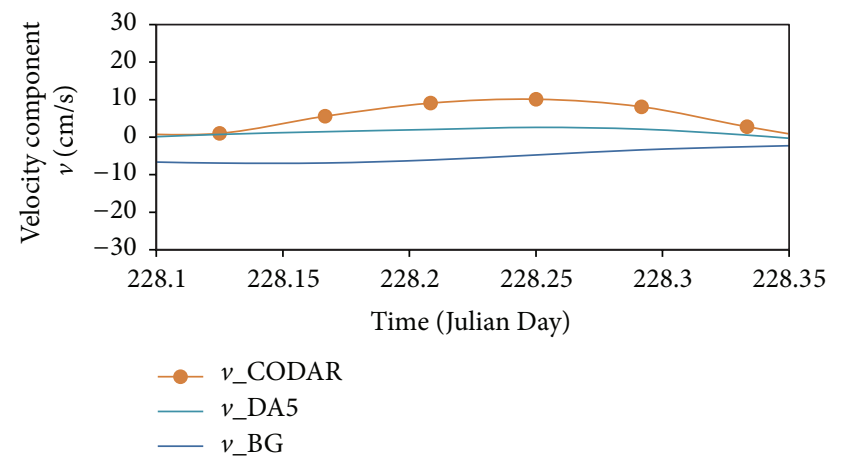

FIGURE 12: North-south velocity component time series during forecasting period at point $\mathrm{B}$.

over $+6 \mathrm{~h}$ forecast was $1.4 \%$ and $22.9 \%$ for east-west and north-south velocity component, respectively. This indicates that the previous correction of wind shear stress during data assimilation period had positive impacts on both surface velocity components. Great improvements were achieved for north-south velocity component during forecasting period.

4.4. Influences on Vertical Currents. Since only surface currents from Galway Bay radar system were assimilated into the three-dimensional model EFDC, the influence of surface current updating on vertical current profiles was studied in this work using available ADCP data. In order to explore the influence of surface assimilation on vertical currents over the water column, vertical current profiles at depth were measured at each observation step by the ADCP and were used to study the impacts of data assimilation on the vertical current structure during forecasting period. Carpet plots 


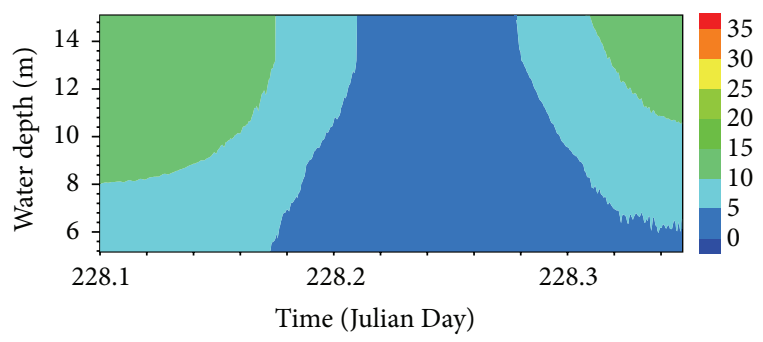

FIGURE 13: Carper plot of currents from model BG in time.

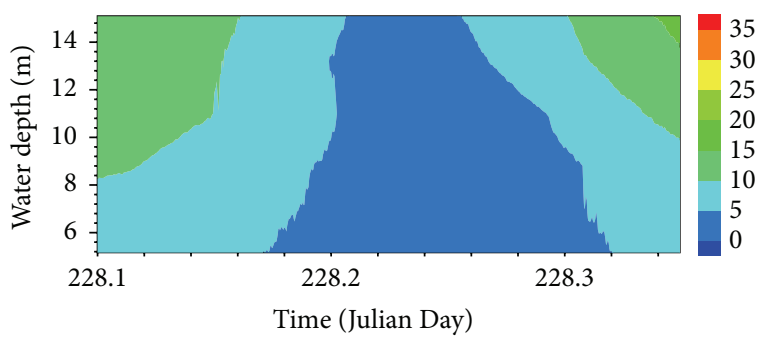

FIGURE 14: Carper plot of currents from model DA5 in time.

from $\mathrm{ADCP}$ and assimilation models are shown in Figures 13-15.

Carpet plots in Figures 13-15 show that assimilation of surface currents using radar data had relatively small impacts on vertical velocity distributions. Temporal trend DA5 changed very little compared with the "free run" BG. It is important to note that $\mathrm{ADCP}$ is not particularly accurate when measuring surface currents [19]. It is also important to remember that the ADCP data are representative of only one point in Galway Bay. Here, the analysis is a guide for future work when more ADCP data are available.

\section{Conclusions}

Wind forcing is a dominant factor in developing surface currents in the coastal zone. The authors have deployed a high-frequency radar system to measure surface current flow fields. These data were compared with ADCP data and modest correlation existed based on Taylor's classification [23]. This has given reasonably good assurance regarding the reliability of the radar data. NUIG wind data and tidal water elevation from OTPS were used to drive the model. The best bottom roughness height for Galway Bay was $0.001 \mathrm{~m}$.

The correction of wind shear stress by assimilating HF radar measurements into the hydrodynamic model improves the model's forecasting ability, comparing with model without data assimilation. The model east-west velocity component has been shown to compare well with radar data, as this direction of currents is dominated by tidal flows; however, the model had a tendency not to accurately predict northsouth velocity component prior to the implementation of data assimilation. After assimilating the radar data into the wind shear stress model boundary condition, the north-south velocity components of model and radar data were considerably closer. The main conclusions are listed as follows:

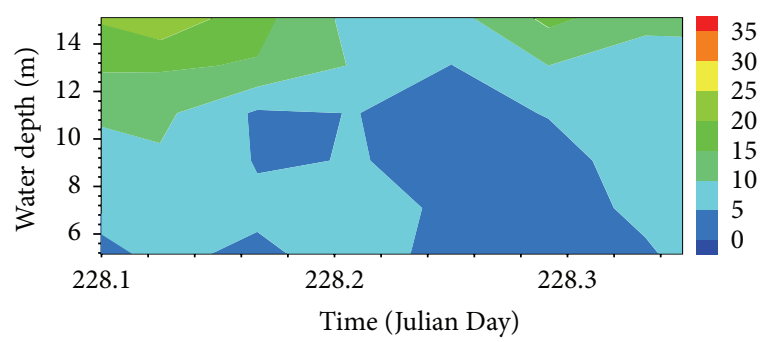

FIGURE 15: Carper plot of ADCP currents in time.

(1) According to the performance during eight-day hindcasting and RMSE values between models and the radar data, the best assimilation parameter was $a=$ -1 for assimilating the radar data to correct the wind shearing stress in model for Galway.

(2) Data assimilation cycle lengths had impacts on extending the influences of data assimilation on forecasts using the temporally interpolated radar data. The best data assimilation cycle length for correcting wind shear stress using the radar data was one minute, namely, model DA5.

(3) The best data assimilation model DA5 can produce better patterns of surface current at two forecasting timesteps, 03:00 and 06:00 Julian Day 228. Significant improvements of vector direction over simulation domain were more than $10 \%$ compared with the "free run" BG at the two typical forecasting timesteps.

(4) Time series of both velocity components were improved at point $\mathrm{B}$ over $+6 \mathrm{~h}$ forecasting compared with the "free run" (model BG).

(5) DASS improvements of north-south velocity component in the best data assimilation DA5 were $15.2 \%$ and $22.9 \%$ for eight-day hindcasting and $+6 \mathrm{~h}$ forecasting, respectively.

(6) Updates of surface currents in model using the HF radar data have impacts on vertical currents, but the effects were very small compared with the "free run."

This research demonstrates that in complex, wind-influenced flows assimilating data into the wind shear stress boundary condition of a coastal hydrodynamic model can improve model predictions significantly. The influence of data assimilation in the following $+6 \mathrm{~h}$ in forecasting model has a positive impact on the surface velocity components. The previous data assimilation process improves the modelling forecasting. There is still a lot of research to be carried out to improve wind-stress formulations so that forecasts are more accurate and more reliable.

\section{Conflict of Interests}

The authors declare that there is no conflict of interests regarding the publication of this paper. 


\section{Acknowledgments}

This work was supported by National University of Ireland, Galway (NUIG), and China Scholarship Council (CSC). Parts of the research were also supported by the Energymare and MAREN2 projects, which are part-funded by the European Regional Development Fund (ERDF) through the Atlantic Area Transnational Programme (INTERREG IV). The authors also would like to thank Informatics Research Unit for Sustainable Engineering (IRUSE) for providing the atmospheric data. They would like to thank Ireland's HighPerformance Computing Centre (ICHEC) for providing computation services.

\section{References}

[1] P. P. Sullivan and J. C. McWilliams, "Dynamics of winds and currents coupled to surface waves," Annual Review of Fluid Mechanics, vol. 42, pp. 19-42, 2010.

[2] P. D. Gaetano, M. Burlando, A. M. Doglioli, and A. A. Petrenko, "Wind forcing effects on coastal circulation and eddy formation around a cape," Ocean Science Discussions, vol. 7, no. 1, pp. 207249, 2010.

[3] J. K. Lewis, I. Shulman, and A. F. Blumberg, "Assimilation of Doppler radar current data into numerical ocean models," Continental Shelf Research, vol. 18, no. 5, pp. 541-559, 1998.

[4] J. Marmain, A. Molcard, P. Forget, A. Barth, and Y. Ourmières, "Assimilation of HF radar surface currents to optimize forcing in the northwestern Mediterranean Sea," Nonlinear Processes in Geophysics, vol. 21, no. 3, pp. 659-675, 2014.

[5] A. Barth, A. Alvera-Azcarate, and R. H. Weisberg, "Assimilation of high-frequency radar currents in a nested model of the West Florida Shelf," Journal of Geophysical Research, vol. 113, pp. 1-15, 2008.

[6] A. Barth, A. Alvera-Azcárate, J.-M. Beckers, J. Staneva, E. V. Stanev, and J. Schulz-Stellenfleth, "Correcting surface winds by assimilating high-frequency radar surface currents in the German Bight," Ocean Dynamics, vol. 61, no. 5, pp. 599-610, 2011.

[7] L. Ren, M. Hartnett, and S. Nash, "Sensitivity tests of direct insertion data assimilation with pseudo measurements," International Journal of Computer and Communication Engineering, vol. 3, no. 6, pp. 460-463, 2014.

[8] A. R. Robinson and P. F. J. Lermusiaux, "Overview of data assimilation," Harvard Reports in Physical/Interdisciplinary Ocean Sciences, Harvard University, Cambridge, Mass, USA, 2000.

[9] G. Evensen, "The Ensemble Kalman Filter: theoretical formulation and practical implementation," Ocean Dynamics, vol. 53, no. 4, pp. 343-367, 2003.

[10] G. Gopalakrishnan and A. F. Blumberg, "Assimilation of HF radar-derived surface currents on tidal-timescales," Journal of Operational Oceanography, vol. 5, no. 1, pp. 75-87, 2012.

[11] E. Ragnoli, S. Zhuk, F. O. Donncha, F. Suits, and M. Hartnett, "An optimal interpolation scheme for assimilation of HF radar current data into a numerical ocean model," in Proceedings of the Oceans Conference, pp. 1-5, IEEE, Hampton Roads, Va, USA, October 2012.

[12] C. L. Robert, E. Blayo, and J. Verron, "Comparison of reducedorder, sequential and variational data assimilation methods in the tropical Pacific Ocean," Ocean Dynamics, vol. 56, no. 5-6, pp. 624-633, 2006.
[13] G. Broquet, C. A. Edwards, A. M. Moore, B. S. Powell, M. Veneziani, and J. D. Doyle, "Application of 4D-Variational data assimilation to the California Current System," Dynamics of Atmospheres and Oceans, vol. 48, no. 1-3, pp. 69-92, 2009.

[14] G. Broquet, A. M. Moore, H. G. Arango, and C. A. Edwards, "Corrections to ocean surface forcing in the California Current System using 4D variational data assimilation," Ocean Modelling, vol. 36, no. 1-2, pp. 116-132, 2011.

[15] D. M. Kaplan, J. Largier, and L. W. Botsford, "HF radar observations of surface circulation off Bodega Bay (northern California, USA)," Journal of Geophysical Research C: Oceans, vol. 110, no. 10, Article ID C10020, pp. 1-25, 2005.

[16] J. Wang, R. Dizaji, and A. M. Ponsford, "Analysis of clutter distribution in bistatic high frequency surface wave radar," in Proceedings of the IEEE Canadian Conference on Electrical and Computer Engineering, vol. 3, pp. 1301-1304, Ontario, Canada, May 2004.

[17] B. K. Haus, J. D. Wang, J. Rivera, J. Martinez-Pedraja, and N. Smith, "Remote radar measurement of shelf currents off Key Largo, Florida, U.S.A.," Estuarine, Coastal and Shelf Science, vol. 51, no. 5, pp. 553-569, 2000.

[18] J. D. Paduan and L. Washburn, "High-frequency radar observations of ocean surface currents," Annual Review of Marine Science, vol. 5, pp. 115-136, 2013.

[19] F. J. Kelly, J. S. Bonner, J. C. Perez et al., "A comparison of near-surface current measurements by ADCP and HF-Radar on the West Florida shelf," in Proceedings of the 7th IEEE/OES Working Conference on Current Measurement Technology, pp. 70-74, IEEE, March 2003.

[20] I. Shulman and J. D. Paduan, "Assimilation of HF radar-derived radials and total currents in the Monterey Bay area," Deep-Sea Research Part II: Topical Studies in Oceanography, vol. 56, no. 3-5, pp. 149-160, 2009.

[21] J. D. Paduan and I. Shulman, "HF radar data assimilation in the Monterey Bay area," Journal of Geophysical Research C, vol. 109, no. 7, pp. 434-446, 2004.

[22] L. K. Shay, H. C. Graber, D. B. Ross, and R. D. Chapman, "Mesoscale ocean surface current structure detected by highfrequency radar," Journal of Atmospheric \& Oceanic Technology, vol. 12, no. 4, pp. 881-900, 1995.

[23] R. Taylor, "Interpretation of the correlation coefficient: a basic review," Journal of Diagnostic Medical Sonography, vol. 6, no. 1, pp. 35-39, 1990.

[24] J. M. Hamrick, "A three-dimensional environmental fluid dynamics computer code: therotical and computatonal aspects," Special Report in Applied Marine Science and Ocean Engineering, Virginia Institute of Marine Science, 1992.

[25] R. Zou, S. Carter, L. Shoemaker, A. Parker, and T. Henry, "An integrated hydrodynamic and water quality modeling system to support nutrient TMDL development for Wissahickon Creek," Journal of Environmental Engineering, vol. 132, pp. 555-566, 2006.

[26] K.-R. Jin and Z.-G. Ji, "Case study: modeling of sediment transport and wind-wave impact in Lake Okeechobee," Journal of Hydraulic Engineering, vol. 130, no. 11, pp. 1055-1067, 2004.

[27] F. O’Donncha, M. Hartnett, and S. Nash, "Physical and numerical investigation of the hydrodynamic implications of aquaculture farms," Aquacultural Engineering, vol. 52, pp. 14-26, 2013.

[28] F. O'Donncha, M. Hartnett, S. Nash, L. Ren, and E. Ragnoli, "Characterizing observed circulation patterns within a bay using HF radar and numerical model simulations," Journal of Marine Systems, vol. 142, pp. 96-110, 2015. 
[29] L. Wen, Three-dimensional hydrodynamic modelling in Galway Bay [Ph.D. thesis], University College Galway, 1995.

[30] D. Nagle, Modelling and observation of wind-driven circulation in Galway Bay [M.S. thesis], National University of Ireland, Galway, Ireland, 2013.

[31] J. M. Hamrick, "Theoretical and computational aspects of the generalized vertical coordinate option in the EFDC model," EFDC Technical Memorandum, US Environmental Protection, Fairfax, Va, USA, 2006.

[32] C. Wang, Y. Sun, and X. Zhang, "Numerical simulation of 3D tidal currents based on the EFDC model in Jiaozhou bay," Periodical of Ocean University of China, vol. 38, pp. 833-840, 2008.

[33] J. Wu, "Wind stress coefficients over sea surface near neutral conditions-a revisit," Journal of Physical Oceanography, vol. 10, no. 5, pp. 727-740, 1980.

[34] B. J. Robson, "When do aquatic systems models provide useful predictions, what is changing, and what is next?" Environmental Modelling \& Software, vol. 61, pp. 287-296, 2014.

[35] N. Margvelashvili, J. Andrewartha, M. Herzfeld, B. J. Robson, and V. E. Brando, "Satellite data assimilation and estimation of a 3D coastal sediment transport model using error-subspace emulators," Environmental Modelling \& Software, vol. 40, pp. 191-201, 2013.

[36] H. H. Shen, A. H. D. Cheng, K.-H. Wang, M. H. Teng, and C. C. K. Liu, Environmental Fluid Mechanics: Theories and Applications, American Society of Civil Engineers, Reston, Va, USA, 2002.

[37] Y. Toba, "Local balance in the air-sea boundary processes-III. On the spectrum of wind waves," Journal of the Oceanographical Society of Japan, vol. 29, no. 5, pp. 209-220, 1973. 

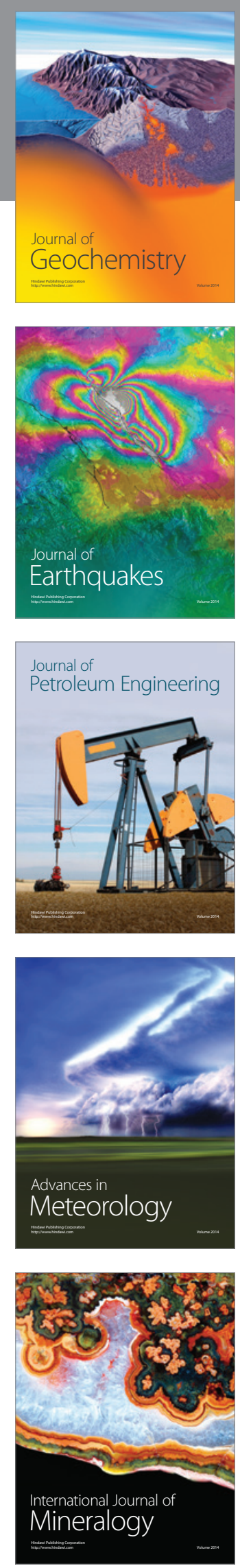
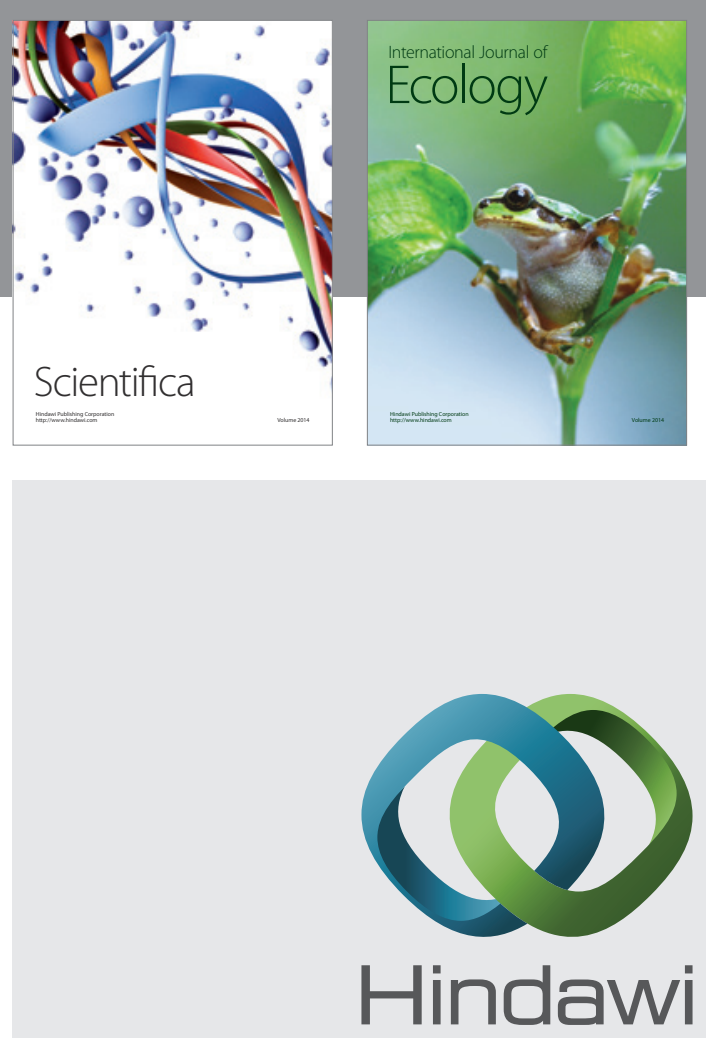

Submit your manuscripts at

http://www.hindawi.com
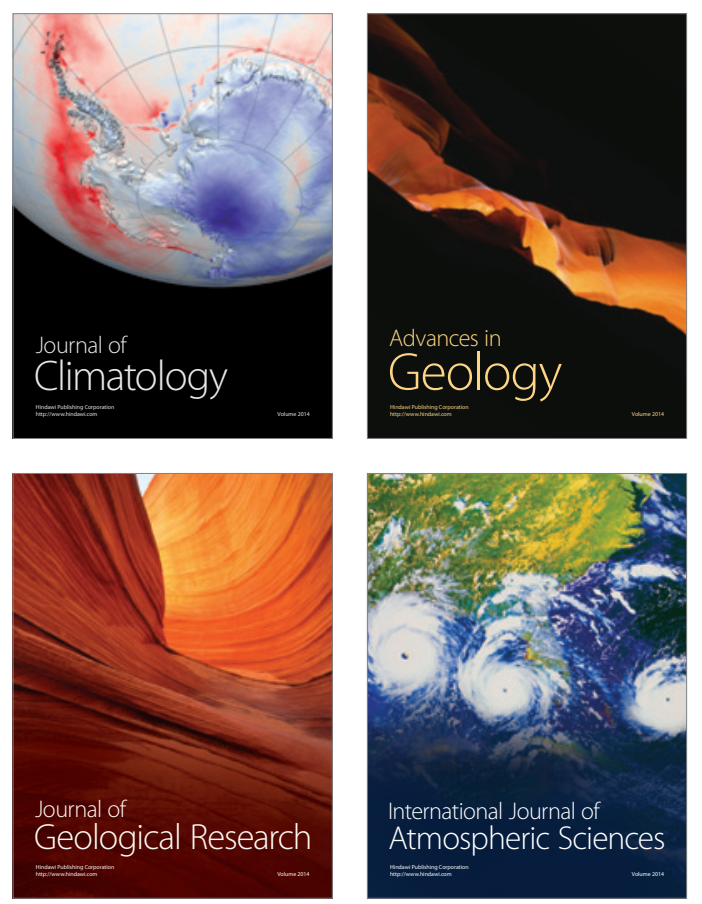

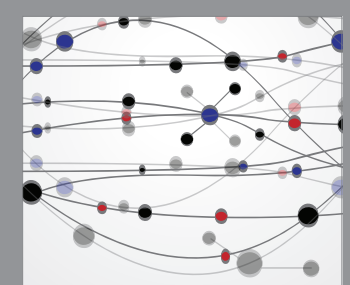

The Scientific

\section{World Journal}
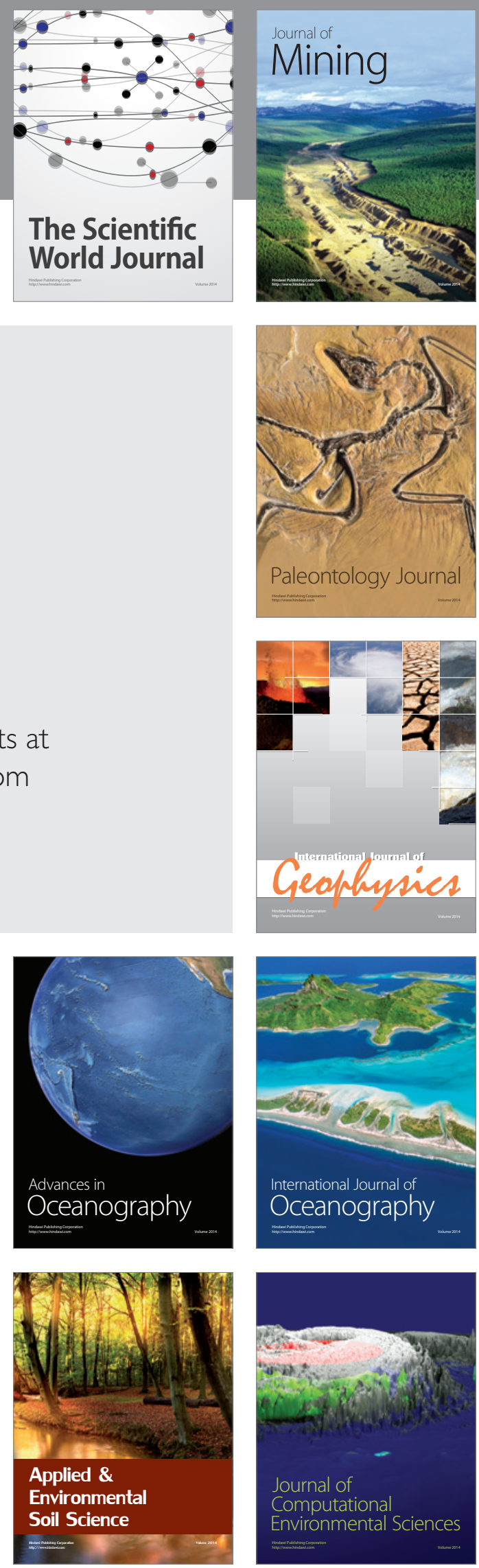